\title{
New generation of cage-type current shunts developed using model analysis
}

\author{
Věra Nováková Zachovalová, Martin Šíra, Pavel Bednář, Stanislav Mašláň \\ Czech Metrology Institute, Okruzni 3163800 Brno, Czech Republic
}

\section{ABSTRACT}

This paper describes a new generation of cage-type ac-dc current shunts from $30 \mathrm{~mA}$ up to $10 \mathrm{~A}$, developed using a lumped circuit element model. Comparison of the calculated and measured values shows agreement better than $6 \mathrm{ppm}$ in the ac-dc difference at frequencies up to $100 \mathrm{kHz}$.

\section{Section: RESEARCH PAPER}

Keywords: Current shunt; Current measurement; Phase measurement; Electric variables measurement

Citation: Věra Nováková Zachovalová, Martin Šíra, Pavel Bednář, Stanislav Mašláň, New generation of cage-type current shunts developed using model analysis, Acta IMEKO, vol. 4, no. 3, article 10, September 2015, identifier: IMEKO-ACTA-04 (2015)-03-10

Editor: Paolo Carbone, University of Perugia, Italy

Received February 13, 2015; In final form April 8, 2015; Published September 2015

Copyright: @ 2015 IMEKO. This is an open-access article distributed under the terms of the Creative Commons Attribution 3.0 License, which permits unrestricted use, distribution, and reproduction in any medium, provided the original author and source are credited

Funding: This work was supported by Czech Metrology Institute, Czech Republic.

Corresponding author: Věra Nováková Zachovalová, e-mail: vnovakovazachovalova@cmi.cz

\section{INTRODUCTION}

At national metrology institutes (NMI) shunts of special designs are used for high accuracy current measurements converting a current from the working level to a voltage convenient for the input of a meter. These shunts are mainly used in power and power quality measurement systems and in ac-dc current transfer difference measurement systems. The ac$\mathrm{dc}$ current transfer difference serves for derivation of a root mean square (RMS) value of an AC current from a dc current of the same nominal level It can be defined as the relative difference between the RMS value of the ac current and the dc current of the same nominal level and can be measured by devices called thermal converters.

In recent years the shunts of three different designs for high accuracy current measurements were developed at several NMIs:

- foil shunts [1] are built using resistive manganin or zeranin foils. They are distinguished by a lower ac-dc difference and phase angle error compared with cage type current shunts but on the other hand their temperature and power coefficient are larger.

- cage shunts [2]-[6] are built using a symmetrical construction of printed circuit board (PCB) with insoldered discrete resistors. They are characterized by low temperature and power coefficients, but their ac-dc difference and phase angle error are larger compared with foil shunts.

- coaxial shunts [7] are made using disk structures, either with surface mount (SMD) resistors or resistive layers. Their design is really compact but their frequency characteristic is the worst of all three shunt designs.

At the Czech Metrology Institute (CMI) the cage design was used to build a first (original) series of current shunts in 2008 [6]. In subsequent research a calculable model of the CMI cage shunt was developed using lumped circuit elements. The transimpedance, ac-dc difference and also the phase angle error of a shunt can be derived from the model [9].

The goal of this research was to build a new generation of cage shunts from $30 \mathrm{~mA}$ up to $10 \mathrm{~A}$ based on a model analysis for the purpose of optimizing their construction to achieve the lowest possible ac-dc difference and phase angle error.

\section{CMI CAGE-TYPE CURRENT SHUNTS CONSTRUCTION AND MODELING}

The original CMI's shunts were developed to be suitable for use with planar multijunction thermal converters (PMJTC) to establish an AC-DC current transfer difference measurement system at CMI in 2008 [6]. 
The voltage drop across every shunt in parallel with a $90 \Omega$ PMJTC is $1 \mathrm{~V}$ at nominal current. The number, value and type of resistors are different in each shunt (see Table 1). The temperature coefficient of the shunts was reduced by using a suitable combination of resistors S102 with different temperature coefficients (one third of S102C and two thirds of S102K), except for the $30 \mathrm{~mA}$ shunt with Z201 resistors, which temperature coefficient is below $1 \mathrm{ppm} / \mathrm{K}$ [6], [8].

The physical design of the original CMI shunts is shown in Figure 1 (detailed in Figure 2).

The shunts are constructed using single-sided and doublesided fibreglass-epoxy PCB material (FR4 with permittivity 5.45 and loss factor 0.0205 ) of $2 \mathrm{~mm}$ thickness with mounted Vishay foil Z201 or S102 resistors and can be split up in the following construction parts [6], [9]:

- input connector;

- input part (two disks made of single-sided PCB);

- crossbars made of double-sided PCB;

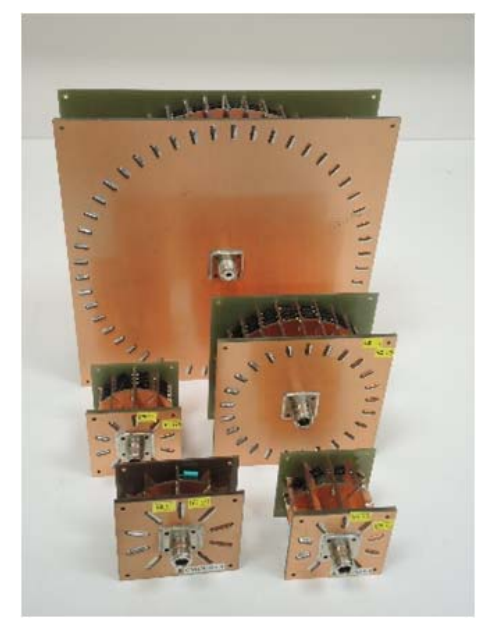

Figure 1. The original CMI shunts.

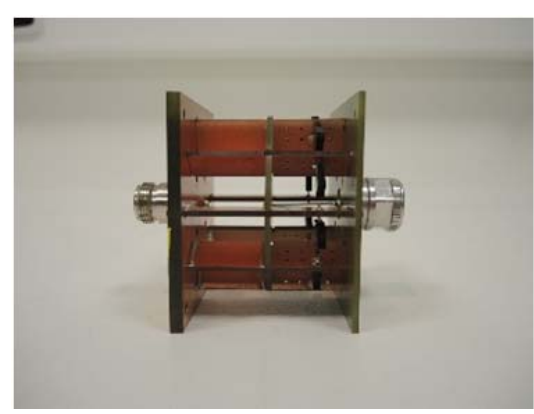

Figure 2. The design of the original $100 \mathrm{~mA}$ shunt.
Table 1. General parameters of the original shunts.

\begin{tabular}{|c|c|c|c|c|}
\hline $\begin{array}{l}\text { Nominal } \\
\text { current }\end{array}$ & $\begin{array}{c}\text { Resistance } \\
(\Omega)\end{array}$ & $\begin{array}{c}\text { Number and } \\
\text { value of } \\
\text { resistors }\end{array}$ & $\begin{array}{l}\text { Type of } \\
\text { resistors }\end{array}$ & PCB type \\
\hline $30 \mathrm{~mA}$ & 50 & $3 \times 150 \Omega$ & Z201 & FR4 \\
\hline $100 \mathrm{~mA}$ & 10 & $10 \times 100 \Omega$ & $\begin{array}{l}3 x \mathrm{~S} 102 \mathrm{C} \\
7 \times \mathrm{S} 102 \mathrm{~K}\end{array}$ & FR4 \\
\hline $300 \mathrm{~mA}$ & 3.3 & $30 \times 100 \Omega$ & $\begin{array}{l}10 x \mathrm{~S} 102 \mathrm{C} \\
20 x \mathrm{~S} 102 \mathrm{~K}\end{array}$ & FR4 \\
\hline $1 \mathrm{~A}$ & 1 & $100 \times 100 \Omega$ & $\begin{array}{l}33 x \text { S102C } \\
67 x \text { S102K }\end{array}$ & FR4 \\
\hline $10 \mathrm{~A}$ & 0.1 & $100 \times 10 \Omega$ & $\begin{array}{l}33 \times \text { S102C } \\
67 \times \text { S102K }\end{array}$ & FR4 \\
\hline
\end{tabular}

- resistors;

- output part (circle and disk made of single-sided PCB and an aluminium wire connected between circle and output connector);

- output connector.

The input connector brings the current to the input disks, which spread the current through the crossbars. Each crossbar carries a fraction of the input current to resistors connected in parallel. The output part senses the voltage drop across the resistors.

To each construction part a two-port element was assigned and their cascade concatenation led to the development of the shunt model (see Figure 3). Each two-port was determined based on the physical design of the related construction part, for instance the crossbars are made from double-sided PCB with a leakage capacitance and resistance $C_{\mathrm{b}}$ and $R_{\mathrm{pb}}$ between the copper layers, and the copper layer also has some inductance $L_{\mathrm{b}}$ and resistance $R_{\mathrm{b}}$ ) [9].

The product of the cascade matrixes assigned to the twoports defines the cascade matrix of the model [9]:

$\hat{A}_{\mathrm{S}}=\hat{A}_{\mathrm{CI}} \hat{A}_{\mathrm{I}} \hat{A}_{\mathrm{B}} \hat{A}_{\mathrm{R}} \hat{A}_{\mathrm{O}} \hat{A}_{\mathrm{CO}}$

where $\hat{A}_{\mathrm{CI}}, \hat{A}_{\mathrm{I}}, \hat{A}_{\mathrm{B}}, \hat{A}_{\mathrm{R}}, \hat{A}_{\mathrm{O}}$ and $\hat{A}_{\mathrm{CO}}$ are cascade matrixes of individual two-ports according to Figure 3.

During measurements the output of the shunt is loaded by the device that measures the voltage drop across the shunt. Therefore it is necessary to include this load into the model. Then, the cascade matrix of the loaded shunt model is [9]:

$\hat{A}=\hat{A}_{\mathrm{S}} \hat{A}_{\mathrm{L}}=\left[\begin{array}{ll}\hat{a}_{11} & \hat{a}_{12} \\ \hat{a}_{21} & \hat{a}_{22}\end{array}\right]$

where $\hat{A}_{\mathrm{L}}$ is cascade matrix assigned to the load and $\hat{a}_{11}, \hat{a}_{12}$, $\hat{a}_{21}$ and $\hat{a}_{22}$ are elements of matrix $\hat{A}$. Element $\hat{a}_{21}$ can be

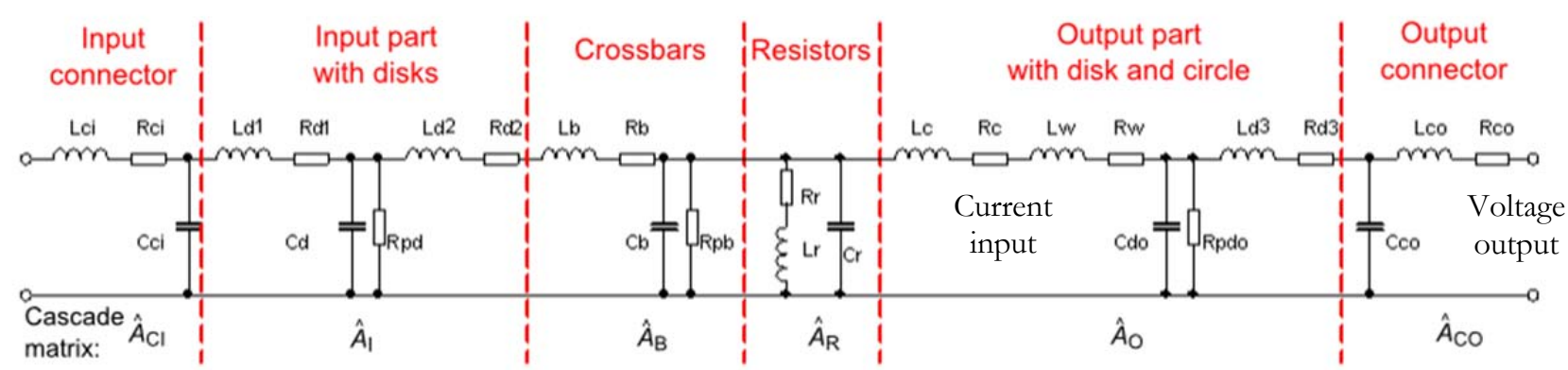

Figure 3. The lumped element model of the shunts. 
used for calculation of the transimpedance of the shunt [9]:

$$
\hat{Z}_{\mathrm{T}}=\frac{1}{\hat{a}_{21}} \text {. }
$$

From the transimpedance the phase-angle error and the acdc difference can be derived easily [9].

This model is based on calculations of all component values from the geometry and material properties. Therefore it was necessary to be familiar with the dielectric properties of the PCB (permittivity, loss factor) and the capacitance and inductance of the resistor, which had to be measured [9].

Evaluation of associated uncertainties of the model was done by means of the Monte Carlo method [9]. [9].

A detailed description of the model calculation is given in

The model was validated by comparison of the calculated and measured values of the original shunts which showed agreement better than $6 \mathrm{ppm}$ in the ac-dc difference and 110 $\mu \mathrm{rad}$ in the phase angle error at frequencies up to $100 \mathrm{kHz}$ [9].

\section{CONSTRUCTION IMPROVEMENTS}

The shunt model can be used to determine the sensitivity of the output quantities to the modification of the input quantities, resulting in improvements to the construction of the shunts [9].

\subsection{Theoretical analysis}

The sensitivity of the calculated values of the ac-dc difference and phase angle error to modification of the input quantities of the model was investigated using parametric simulation.

Calculations indicated that some of the input quantities have a significant influence and some have an insignificant influence on the calculated values of the ac-dc difference and phase angle error. The following input quantities of the model were found to have significant influence on the calculated values [9]:

- capacitance and inductance of the resistors;

- relative permittivity and loss factor of the PCB;

- thickness of the PCB;

- number of crossbars and geometric dimensions.

It was found that the influence of all these input quantities increases with frequency (see the example of the ac-dc difference and phase angle error dependence on frequency with modification of the PCB permittivity in Figure 4 and Figure 5).

By converting the data to a single frequency point it was ascertained that the dependence of the ac-dc difference and phase angle error on the modification of the relevant input quantities is linear except for the dependence on the modification of PCB thickness (see the example of the ac-dc difference and phase angle error dependence on modification

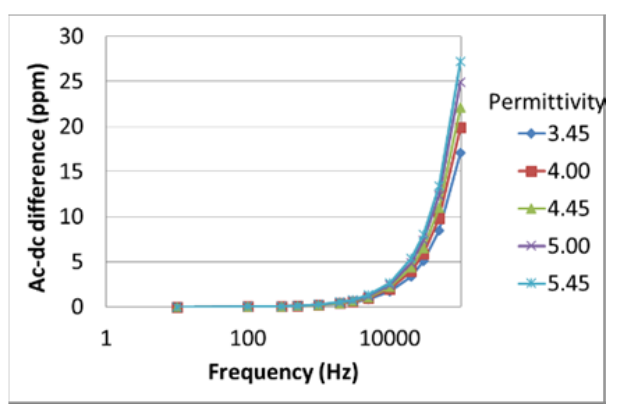

Figure 4. Ac-dc difference dependence on frequency with modification of PCB permittivity calculated for a $100 \mathrm{~mA}$ shunt.

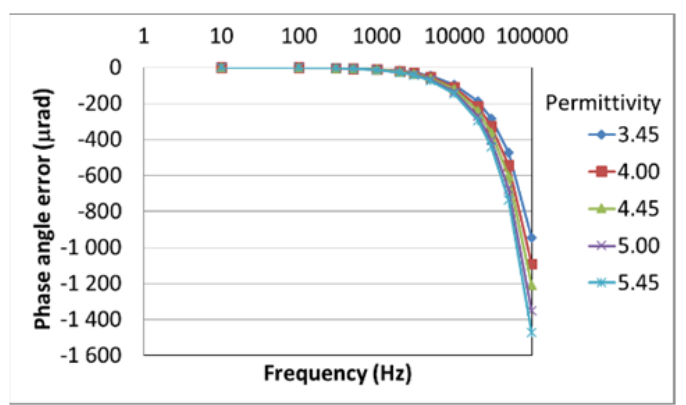

Figure 5. Phase angle error dependence on frequency with modification of PCB permittivity calculated for a $100 \mathrm{~mA}$ shunt.

of PCB permittivity and PCB thickness in Figure 6 to Figure 9, calculated at $100 \mathrm{kHz}$ ).

In the next step the calculation of sensitivity coefficients was performed to extract information about the vastness of influence of a single input quantity. The sensitivity coefficients were calculated as:

$C_{\mathrm{yx}}=\frac{\Delta y}{\Delta x}$

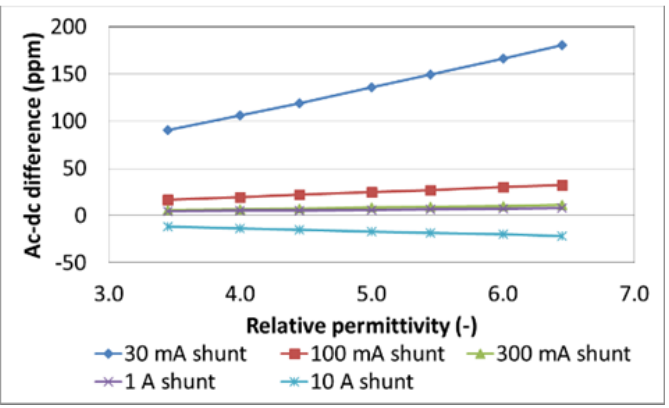

Figure 6. Ac-dc difference dependence on modification of the PCB permittivity calculated at $100 \mathrm{kHz}$.

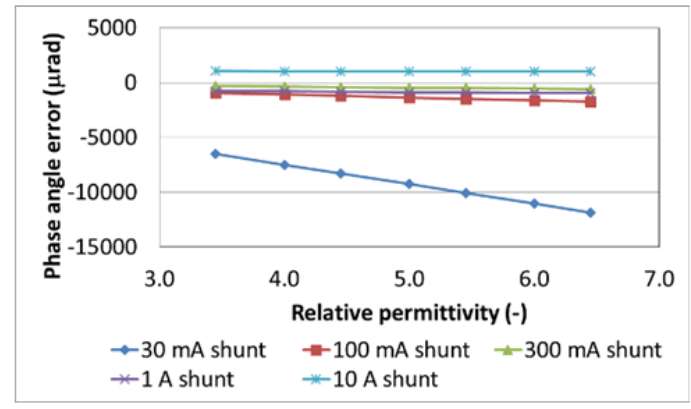

Figure 7. Phase angle error dependence on modification of the PCB permittivity calculated at $100 \mathrm{kHz}$.

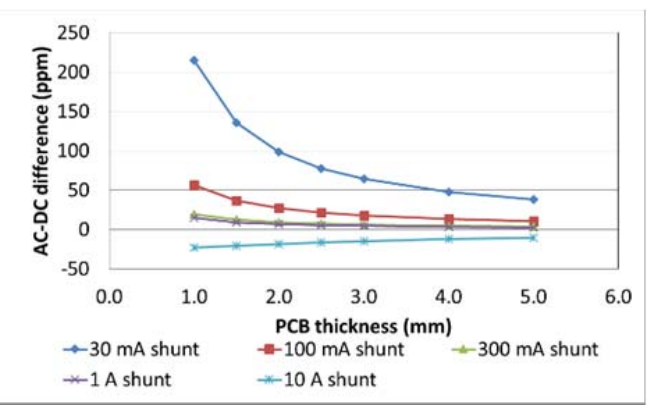

Figure 8. Ac-dc difference dependence on modification of the PCB thickness calculated at $100 \mathrm{kHz}$. 


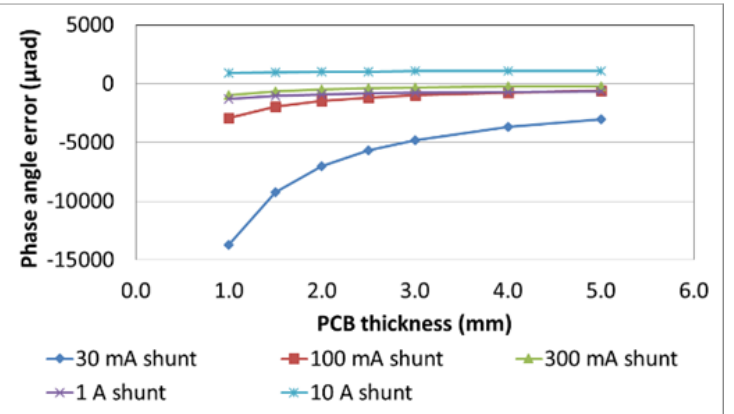

Figure 9. Phase angle error dependence on modification of the PCB thickness calculated at $100 \mathrm{kHz}$.

where $\Delta y$ represents a change of the output quantity (ac-dc difference or phase angle error) corresponding to a change $\Delta x$ of the selected input quantity.

Ac-dc difference and phase angle error sensitivity coefficients calculated at $100 \mathrm{kHz}$ are shown in Table 2 and Table 3 . The values of the sensitivity coefficients are different for the low-current and high-current shunts. This indicates that the optimization of the shunts construction depends on different input quantities for the low-current and high-current shunts construction.

The ac-dc difference of the low-current shunts is affected by the dielectric properties and thickness of the PCB and slightly also by geometrical dimensions. The ac-dc difference of high-current shunts depends more on the disk size and less on the dielectric properties and thickness of the PCB. The

Table 2. Ac-dc difference sensitivity coefficients calculated at $100 \mathrm{kHz}$.

\begin{tabular}{|c|c|c|c|c|c|}
\hline Input quantity & $\begin{array}{l}30 \mathrm{~mA} \\
\text { shunt }\end{array}$ & $\begin{array}{c}100 \mathrm{~mA} \\
\text { shunt }\end{array}$ & $\begin{array}{c}1 \mathrm{~A} \\
\text { shunt }\end{array}$ & $\begin{array}{c}10 \mathrm{~A} \\
\text { shunt }\end{array}$ & $\begin{array}{c}\text { Unit of } \\
\text { sensitivity } \\
\text { coefficient }\end{array}$ \\
\hline Capacitance of resistors & 0.4 & 0.1 & 0.0 & 0.0 & $\mathrm{ppm} / \mathrm{pF}$ \\
\hline Inductance of resistors & 0.0 & 0.0 & 0.0 & -0.1 & $\mathrm{ppm} / \mathrm{nH}$ \\
\hline PCB thickness & -44.3 & -11.3 & -2.9 & 3.2 & $\mathrm{ppm} / \mathrm{mm}$ \\
\hline PCB permittivity & 30.2 & 5.1 & 1.3 & -3.2 & $\mathrm{ppm}$ \\
\hline PCB loss factor & 57.8 & 12.9 & 4.0 & 1.1 & $\mathrm{ppm} / 10^{-2}$ \\
\hline With of crossbars & 5.5 & 1.8 & 0.5 & 0.1 & $\mathrm{ppm} / \mathrm{mm}$ \\
\hline Length of crossbars & 2.8 & 0.4 & 0.1 & 0.0 & $\mathrm{ppm} / \mathrm{mm}$ \\
\hline Size of disks & 21.4 & 3.1 & -0.3 & -5.3 & $\mathrm{ppm} / \mathrm{cm}$ \\
\hline
\end{tabular}

Table 3. Phase angle error sensitivity coefficients calculated at $100 \mathrm{kHz}$.

\begin{tabular}{lccccc}
\hline \multicolumn{1}{c}{ Input quantity } & $\begin{array}{c}\mathbf{3 0} \mathbf{m A} \\
\text { shunt }\end{array}$ & $\begin{array}{c}\mathbf{1 0 0} \\
\mathbf{m A} \\
\text { shunt }\end{array}$ & $\begin{array}{c}\text { 1 A } \\
\text { shunt }\end{array}$ & $\begin{array}{c}\text { 10 A } \\
\text { shunt }\end{array}$ & $\begin{array}{c}\text { Unit of } \\
\text { sensitivity } \\
\text { coefficient }\end{array}$ \\
\hline Capacitance of resistors & -94.1 & -62.8 & -62.8 & -6.3 & $\mu \mathrm{rad} / \mathrm{pF}$ \\
Inductance of resistors & 4.18 & 6.3 & 6.3 & 62.8 & $\mu \mathrm{rad} / \mathrm{nH}$ \\
PCB thickness & 2673.9 & 572.9 & 160.1 & 41.5 & $\mu \mathrm{rad} / \mathrm{mm}$ \\
PCB permittivity & -1782.0 & -262.8 & -73.4 & -19.1 & $\mu \mathrm{rad}$ \\
PCB loss factor & 0.8 & 0.0 & 0.0 & -0.2 & $\mu \mathrm{rad} / 10^{-2}$ \\
With of crossbars & -342.6 & -90.9 & -22.7 & -4.5 & $\mu \mathrm{rad} / \mathrm{mm}$ \\
Length of crossbars & -157.4 & -18.2 & -4.5 & -0.9 & $\mu \mathrm{rad} / \mathrm{mm}$ \\
Size of disks & -1278.5 & -239.5 & -59.5 & -5.3 & $\mu \mathrm{rad} / \mathrm{cm}$ \\
\hline
\end{tabular}

capacitance and inductance of the resistors do not influence the ac-dc difference of all shunts.

The phase angle error of the low-current shunts is influenced by the relative permittivity and thickness of the PCB, by geometric dimensions and slightly also by the capacitance and inductance of the resistors. The phase angle error of highcurrent shunts is affected mainly by the inductance of the resistors, but also by the thickness of the PCB and slightly by the relative permittivity. The influence of the loss factor on the phase angle error is negligible for all shunts.

\subsection{Construction of the new generation cage-type current shunts}

Figure 10 shows the new generation of cage-type shunts from $30 \mathrm{~mA}$ up to $10 \mathrm{~A}$ developed at CMI. The voltage drop across every shunt is $0.6 \mathrm{~V}$ at nominal current being convenient for use either with PMJTC in the measurement set up of the acdc current transfer difference established in 2008 [6] or with analogue to digital converters (ADC) in view of the development of a new sampling wattmeter measurement system.

The improvements to the shunts construction resulted from the theoretical analysis of the lumped element model described above. General information about resistors and PCB material used for their construction are in Table 4.

The low current shunts (up to $1 \mathrm{~A}$ ) were constructed using the high frequency PCB material RO4350B with better dielectric properties (permittivity $=3.6$, loss factor $=0.0031$ ) than the previously used FR4 material. The thickness of the PCB was reduced from $2 \mathrm{~mm}$ down to $1.524 \mathrm{~mm}$. Geometrical

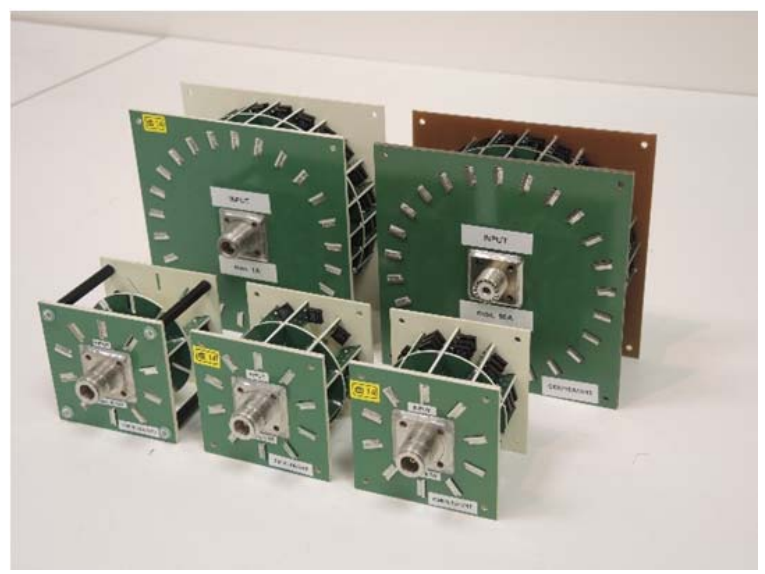

Figure 10. The new generation of cage-type shunts.

Table 4. General parameters of the new shunts.

\begin{tabular}{|c|c|c|c|c|}
\hline $\begin{array}{l}\text { Nominal } \\
\text { current }\end{array}$ & $\begin{array}{c}\text { Resistance } \\
(\Omega)\end{array}$ & $\begin{array}{c}\text { Number and } \\
\text { value of } \\
\text { resistors }\end{array}$ & $\begin{array}{l}\text { Type of } \\
\text { resistors }\end{array}$ & PCB type \\
\hline $30 \mathrm{~mA}$ & 20 & $3 \times 60 \Omega$ & Z201 & RO4350B \\
\hline $100 \mathrm{~mA}$ & 6 & $10 \times 60 \Omega$ & $\begin{array}{l}3 x \mathrm{~S} 102 \mathrm{C} \\
7 \times \mathrm{S} 102 \mathrm{~K}\end{array}$ & RO4350B \\
\hline $300 \mathrm{~mA}$ & 2 & $30 \times 60 \Omega$ & $\begin{array}{l}10 \times \mathrm{S} 102 \mathrm{C} \\
20 \times \mathrm{S} 102 \mathrm{~K}\end{array}$ & RO4350B \\
\hline $1 \mathrm{~A}$ & 0.6 & $50 \times 30 \Omega$ & $\begin{array}{l}17 x \mathrm{~S} 102 \mathrm{C} \\
33 \times \mathrm{S} 102 \mathrm{~K}\end{array}$ & RO4350B \\
\hline $10 \mathrm{~A}$ & 0.06 & $100 \times 6 \Omega$ & $\begin{array}{l}33 \times \text { S102C } \\
67 \times \text { S102K }\end{array}$ & FR4 \\
\hline
\end{tabular}


dimensions should be kept as small as possible to obtain low frequency dependence of the shunt transimpedance. The dimensions of the $30 \mathrm{~mA}$ shunt were slightly reduced to be the same as for the $100 \mathrm{~mA}$ shunt. Also the number of the $30 \mathrm{~mA}$ shunt crossbars was minimized to only three and the $30 \mathrm{~mA}$ shunt construction was reinforced using distance struts. The dimensions of the $100 \mathrm{~mA}, 300 \mathrm{~mA}$ and $1 \mathrm{~A}$ shunts were not modified. The length of the crossbars was reduced in all shunts.

The 10 A shunt was constructed using low frequency PCB (FR4) because of the inconsiderable influence of its dielectric properties to the calculated values. Only the thickness of the FR4 was reduced to $1.5 \mathrm{~mm}$. Dimensions of the $10 \mathrm{~A}$ shunt were reduced to be the same as the original $1 \mathrm{~A}$ shunt.

The length of the crossbars was also reduced to be as short as possible. Resistors mounted in the shunts are the same type as in previous construction because no other resistors with lower inductance were found.

Including all of these modifications into the model showed a reduction in the ac-dc difference below $3.5 \mathrm{ppm}$ at frequencies up to $100 \mathrm{kHz}$ (see Table 5).

\section{COMPARISON OF CALCULATED AND MEASURED VALUES OF THE NEW SHUNTS}

The ac-dc difference of the shunts was measured using an automated measurement system developed for the ac-dc current transfer difference set up (see Figure 11), which was established in 2008 [6] and improved in 2010 [8].

A reference and a calibrated standard are connected in series. Ac and dc currents are applied through a transconductance amplifier Clarke\&Hess 8100, which is alternately connected to a dc and ac voltage source (multifunction calibrators Fluke or Datron) using an automated switch OFMET. The standards are comprised of a shunt loaded by a thermal converter [8].

The uncertainty budget of such a complicated measurement set up covers contributions of the reference standard and its level dependence, the reproducibility of the measured ac-dc difference (standard deviation), influences of the series connection of both standards and measurement set up, the

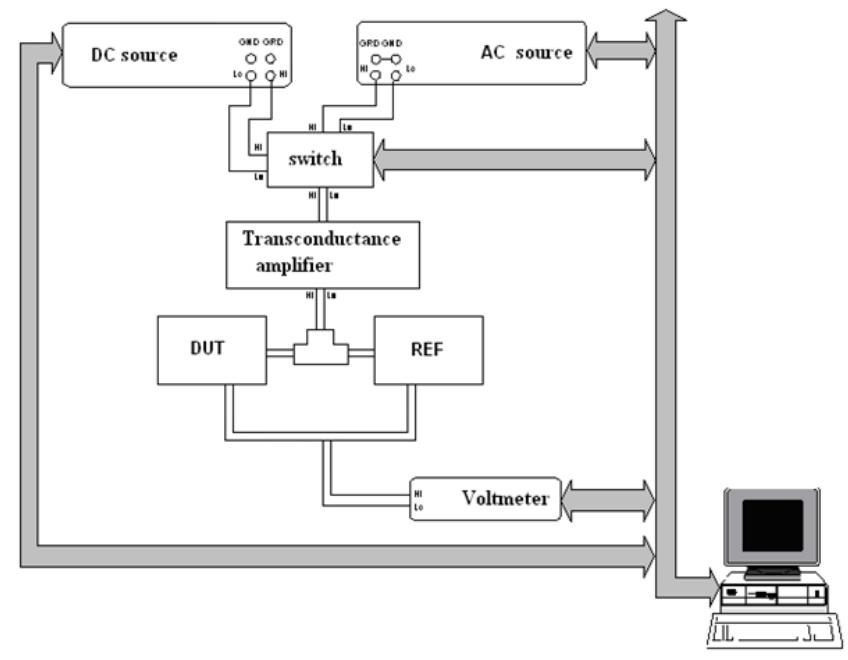

Figure 11. The measurement system of the ac-dc current transfer difference.

frequency dependence, and the influence of temperature. A detailed description of the uncertainty calculation can be found in [8].

During the measurements of the new generation of the shunts the output of the shunts was loaded by a $90 \Omega / 10 \mathrm{~mA}$ PMJTC, which was included in the model.

Table 5 shows the agreement between the measured and calculated values of the ac-dc differences of the new shunts to be better than $6 \mathrm{ppm}$ at frequencies up to $100 \mathrm{kHz}$.

Table 6 shows the comparison of the measured ac-dc differences of the original and new shunts. For all shunts a significant reduction of the ac-dc difference was accomplished. The most significant reduction of the ac-dc difference was achieved for the $30 \mathrm{~mA}$ shunt, which construction was modified most of all shunts (see Section 3.2). Following the sensitivity coefficients calculation (see Table 2) the $30 \mathrm{~mA}$ shunt construction is also most sensitive to the modification of the input quantities in comparison with the other shunts. Because of the significant modification of the $30 \mathrm{~mA}$ shunt construction and its high sensitivity to these modification its ac-

Table 5. Calculated and measured values of the ac-dc difference for the new shunts with associated uncertainties for $\mathrm{k}=1$.

\begin{tabular}{|c|c|c|c|c|c|c|c|c|}
\hline \multirow{2}{*}{$\begin{array}{l}\text { Nominal } \\
\text { current }\end{array}$} & \multirow{2}{*}{ Value } & \multirow{2}{*}{ Ac-dc difference } & \multicolumn{6}{|c|}{ Frequency } \\
\hline & & & $500 \mathrm{~Hz}$ & $1 \mathrm{kHz}$ & $10 \mathrm{kHz}$ & $20 \mathrm{kHz}$ & $50 \mathrm{kHz}$ & $100 \mathrm{kHz}$ \\
\hline \multirow[t]{4}{*}{$30 \mathrm{~mA}$} & $20 \Omega$ & Calculated (ppm) & 0.016 & 0.032 & 0.320 & 0.650 & 1.700 & 3.400 \\
\hline & & Unc. (ppm) & 0.005 & 0.010 & 0.096 & 0.190 & 0.490 & 0.980 \\
\hline & & Measured (ppm) & -0.4 & -0.5 & 1.5 & 2.9 & 4.7 & 7.0 \\
\hline & & Unc. (ppm) & 4.4 & 4.4 & 4.4 & 4.4 & 4.4 & 4.7 \\
\hline \multirow[t]{4}{*}{$100 \mathrm{~mA}$} & $6 \Omega$ & Calculated (ppm) & 0.011 & 0.022 & 0.022 & 0.440 & 1.110 & 2.240 \\
\hline & & Unc. (ppm) & 0.003 & 0.007 & 0.067 & 0.130 & 0.340 & 0.680 \\
\hline & & Measured (ppm) & -0.9 & -1.7 & 0.7 & 3.4 & 4.4 & 6.4 \\
\hline & & Unc. (ppm) & 6.4 & 6.4 & 6.4 & 6.5 & 6.7 & 7.1 \\
\hline \multirow[t]{4}{*}{$300 \mathrm{~mA}$} & $2 \Omega$ & Calculated (ppm) & 0.004 & 0.008 & 0.075 & 0.150 & 0.350 & 0.620 \\
\hline & & Unc. (ppm) & 0.001 & 0.002 & 0.023 & 0.047 & 0.120 & 0.230 \\
\hline & & Measured (ppm) & 0.9 & 1.1 & 1.1 & 1.9 & 4.3 & 5.5 \\
\hline & & Unc. (ppm) & 7.9 & 7.9 & 7.9 & 8.0 & 8.4 & 8.9 \\
\hline \multirow[t]{4}{*}{$1 \mathrm{~A}$} & $0.6 \Omega$ & Calculated (ppm) & 0.003 & 0.006 & 0.051 & 0.073 & -0.039 & -0.810 \\
\hline & & Unc. (ppm) & 0.001 & 0.002 & 0.020 & 0.039 & 0.098 & 0.210 \\
\hline & & Measured (ppm) & -1.4 & -0.8 & -1.5 & 0.5 & 1.3 & -0.3 \\
\hline & & Unc. (ppm) & 9.2 & 9.2 & 9.2 & 9.3 & 9.8 & 10.4 \\
\hline \multirow[t]{4}{*}{$10 \mathrm{~A}$} & $0.06 \Omega$ & Calculated (ppm) & 0.003 & 0.006 & 0.033 & 0.004 & -0.460 & -2.500 \\
\hline & & Unc. (ppm) & 0.000 & 0.001 & 0.005 & 0.013 & 0.067 & 0.270 \\
\hline & & Measured (ppm) & 0.7 & 1.5 & -2.3 & -1.2 & 4.0 & 3.2 \\
\hline & & Unc. (ppm) & 11.3 & 11.3 & 11.3 & 11.4 & 12.1 & 12.8 \\
\hline
\end{tabular}


Table 6. Comparison of the measured ac-dc difference values ( $\mathrm{ppm}$ ) of the original and new shunts generation.

\begin{tabular}{|c|c|c|c|c|c|c|c|c|}
\hline \multirow{2}{*}{$\begin{array}{l}\text { Nominal } \\
\text { current }\end{array}$} & \multirow{2}{*}{ Generation } & \multirow{2}{*}{ Value } & \multicolumn{6}{|c|}{ Frequency } \\
\hline & & & $500 \mathrm{~Hz}$ & $1 \mathrm{kHz}$ & $10 \mathrm{kHz}$ & $20 \mathrm{kHz}$ & $50 \mathrm{kHz}$ & $100 \mathrm{kHz}$ \\
\hline \multirow[t]{2}{*}{$30 \mathrm{~mA}$} & New & $20 \Omega$ & 0 & -1 & 2 & 3 & 5 & 7 \\
\hline & Original & $50 \Omega$ & -1 & 0 & 8 & 20 & 57 & 131 \\
\hline \multirow[t]{2}{*}{$100 \mathrm{~mA}$} & New & $6 \Omega$ & -1 & -2 & 1 & 3 & 4 & 6 \\
\hline & Original & $10 \Omega$ & 1 & -1 & 4 & 9 & 20 & 39 \\
\hline \multirow[t]{2}{*}{$300 \mathrm{~mA}$} & New & $2 \Omega$ & 1 & 1 & 1 & 2 & 4 & 6 \\
\hline & Original & $3.3 \Omega$ & 0 & 0 & 4 & 7 & 13 & 22 \\
\hline \multirow[t]{2}{*}{$1 \mathrm{~A}$} & New & $0.6 \Omega$ & -1 & -1 & -1 & 1 & 1 & 0 \\
\hline & Original & $1 \Omega$ & 1 & -3 & -2 & 2 & 6 & 12 \\
\hline \multirow[t]{2}{*}{$10 \mathrm{~A}$} & New & $0.06 \Omega$ & 1 & 1 & -2 & -1 & 4 & 3 \\
\hline & Original & $0.1 \Omega$ & 1 & -1 & -2 & -3 & -4 & -23 \\
\hline
\end{tabular}

dc difference was decreased by more than 100 ppm.

\section{CONCLUSIONS}

A new generation of the cage-type current shunts from 30 $\mathrm{mA}$ up to $10 \mathrm{~A}$ was developed.

Construction improvements were done based on the results obtained from the analysis of the lumped element model of the original shunts.

Comparison of the calculated and measured values of the new shunts showed an agreement better than $6 \mathrm{ppm}$ in the acdc difference at frequencies up to $100 \mathrm{kHz}$.

Future work will address the comparison of the calculated and measured phase angle errors of the new shunts and the development of high current shunts up to $100 \mathrm{~A}$.

\section{REFERENCES}

[1] Garcocz, M., Scheibenreiter, P., Waldmann, W., Heine, G., "Expanding the Measurement Capability for AC-DC Current Transfer at BEV", 2004 Digest of CPEM Conf, June 2004, pp.461,462.

[2] Filipski, P.S., Boecker, M., "AC-DC current shunts and system for extended current and frequency ranges", IEEE Trans. on Instrum. and Meas., vol.55, No.4, Aug. 2006, pp.1222-1227.
[3] Voljc, B., Lindic, M., Lapuh, R., "Direct Measurement of AC Current by Measuring the Voltage Drop on the Coaxial Current Shunt", IEEE Trans. on Instrum. and Meas., vol.58, No.4, April 2009, pp.863-867.

[4] Voljc, B., Lindic, M., Pinter, B., Kokalj, M., Svetik, Z., Lapuh, R., "Evaluation of a 100 A Current Shunt for the Direct Measurement of AC Current", IEEE Trans. on Instrum. and Meas., vol.62, No.6, June 2013, pp.1675-1680.

[5] Lind, K., Sorsdal, T., Slinde, H., "Design, Modeling, and Verification of High-performance ac-dc Current Shunts from Inexpensive Components", IEEE Trans. on Instrum. and Meas., vol. 57, No. 1, Jan. 2008, pp. 176-181.

[6] Zachovalová, V. N., "AC-DC current transfer difference in CMI”, 2008 Digest of CPEM Conf., 2008, pp. 362-363.

[7] Pogliano, U., Bosco, G. C., Serazio, D., "Coaxial Shunts as ACDC Transfer Standards of Current", IEEE Trans. on Instrum. and Meas., vol. 58, No.4, 2009, p. 872-877.

[8] Zachovalová, V.N., Šira, M., Streit, J., "Current and frequency range extension of $\mathrm{AC}-\mathrm{DC}$ current tranfer difference measurement system at CMI", 2010 Digest of CPEM Conf., 2010, pp.605,606.

[9] Zachovalová, V.N., "On the Current Shunts Modeling”, IEEE Trans. on Instrum. and Meas., vol.63, No.6, June 2014, pp.16201627. 